\title{
Possibilidades políticas da crítica em perspectiva teórica
}

\section{Political possibilities of critique: a theoretical overview}

Gislene Silva ${ }^{1}$, Rosana de Lima Soares ${ }^{2}$ de Santa Catarina, e doutora em Ciências Sociais/Antropologia pela Pontifícia Universidade Católica de São Paulo. Bolsista de produtividade em pesquisa do Conselho Nacional de Desenvolvimento Científico e Tecnológico (CNPq). E-mail: gislenedasilva@gmail.com. 


\section{Resumo}

Este estudo discute possibilidades políticas da crítica em face de diferentes perspectivas teóricas, priorizando, neste momento, contribuições da teoria crítica e dos estudos culturais para se fazer a crítica de mídia. Trabalhamos com a necessidade de se privilegiar objetos concretos em circulação no ambiente midiático e de se considerar também os sistemas de produção e recepção em que as obras se inserem. O objetivo, ao levar em conta a diversidade de objetos midiáticos e a variedade de modos de se fazer a crítica de mídia, é debater a conexão entre as perspectivas da teoria crítica e dos estudos culturais no campo da crítica de mídia, especialmente em cenários fortemente marcados por embates políticos e ideológicos.

Palavras-chave

Crítica de mídia, crítica de televisão, teoria crítica, estudos culturais.

\section{Abstract}

This article discusses political possibilities of criticism in the face of different theoretical approaches, underlining contributions of critical theory and cultural studies to criticize media. We must privilege specific objects in circulation in the media environment, and consider the production and reception systems where such pieces are inserted. Considering the diversity of media objects and the various ways criticizing it, this article aims to discuss the connection between the perspectives of critical theory and cultural studies in the field of media criticism, especially in scenarios strongly marked by political and ideological clashes.

\section{Keywords}

Media criticism, television criticism, critical theory, cultural studies. 
Para discutir possibilidades políticas da crítica de mídia em face de diferentes perspectivas teóricas, priorizamos neste artigo contribuições da teoria crítica e dos estudos culturais para se fazer a crítica de mídia. Começamos o estudo com a apresentação do trabalho de Leah R. Vande Berg e Lawrence A. Wenner em seu livro Television criticism: approaches and aplications, de 1991. Mais do que destacar estudos de caso sobre programas televisivos, os autores demonstram a variedade de gêneros televisivos passíveis de crítica e a diversidade de olhares teórico-metodológicos para os estudos de televisão. A partir daí trabalhamos com a necessidade de se privilegiar objetos concretos em circulação no ambiente midiático e de se considerar também os sistemas de produção e recepção em que as obras se inserem. Ao levar em conta a quantidade de diferentes objetos midiáticos e a amplitude de modos de se fazer a crítica de mídia, pretendemos aqui debater a conexão entre as perspectivas da teoria crítica e dos estudos culturais no campo da crítica de mídia. Estamos nos indagando sobre o papel político da crítica de mídia com base nas contribuições da teoria crítica e dos estudos culturais, especialmente em cenários fortemente marcados por embates políticos e ideológicos. Como premissa, consideramos que cada possibilidade analítica pressupõe uma perspectiva filosófica, uma experiência histórica, uma aproximação teórica e uma escolha de método.

\section{Arranjos entre gêneros televisivos e métodos críticos}

Os autores Leah R. Vande Berg e Lawrence A. Wenner, ao tratarem da crítica de televisão em seu livro, realizam um exercício original no campo dos estudos de mídia. Para os autores, o objetivo desta crítica seria buscar entendimento, explicação e apreciação da televisão como expressão sociocultural e simbólica. Reconhecendo o amadurecimento das análises sobre televisão, organizam diversas opções teórico-metodológicas em que esta mídia tem sido estudada. Os autores salientam a singularidade de tais estudos em relação aos pontos de vista assumidos pelos pesquisadores, que trazem para as análises percepções como se fossem telespectadores que experienciam maneiras distintas de ver televisão. Esta proposição dos autores colabora para pensarmos em diferentes 
combinações teórico-metodológicas no ato da crítica, e na própria crítica como um empreendimento também teórico.

No capítulo I do livro, em que fazem uma introdução ao tema television criticism, Vande Berg e Wenner discutem a distinção entre escrita jornalística sobre televisão e crítica acadêmica de televisão, e problematizam a natureza da crítica de televisão. Quanto à natureza da crítica, ressaltam que a crítica de televisão "não é": necessariamente negativa; história da televisão; teste de hipótese científica; nem mesmo teoria. Destacam, em contraponto, que a crítica de televisão "é" descrição, análise e avaliação de símbolos, relações e padrões para compartilhar uma perspectiva informada. Dizem ainda que a crítica usa uma variedade de métodos críticos para analisar a televisão, e que métodos críticos são simplesmente ferramentas que críticos usam para organizar suas observações, insights e interpretações e comunicá-las de modo sistemático e eficiente, com bons argumentos sustentados em evidências (VANDE BERG; WENNER, 1991, p. 10-11).

Embora caibam aqui algumas discordâncias quanto a este "ser" ou "não ser" crítica de televisão (em especial certa leitura instrumental da ação de criticar), o que nos parece interessante na proposta desses dois autores é a tarefa de levar a sério a televisão, valorizando-a como prática midiática e auxiliando-nos a estudar outras mídias, como é o caso, por exemplo, das mídias noticiosas. Pareceu-nos proveitoso o arranjo que propõem para as abordagens: (i) Abordagens metacríticas: estudos culturais, hermenêutica e estruturalismo/semiótica. (ii) Abordagens críticas: por gêneros televisivos/autoria; mitológica; histórica; sociológica; retórica; etnográfica; dialógica; em estudos de recepção; estudos de gênero (feminino, masculino etc.); análise de discurso. Claro que tal separação exige um pouco mais de complexificação, mas esses dois conjuntos de abordagens nos animam a examinar justamente combinações teórico-metodológicas no ato de criticar diferentes gêneros e produtos midiáticos (VANDE BERG; WENNER, 1991, p. 27-37).

A outra distinção feita pelos autores entre escrita jornalística sobre televisão e crítica acadêmica de televisão tem relevância para este nosso estudo porque, uma vez inserido no campo maior da crítica de mídia, observamos que é necessário 
alargar esse universo de possibilidades, tal como já comentamos em outros textos a respeito de diferentes instâncias, modalidades ou parâmetros do "como fazer para criticar". Possibilidades tais como: estudo das críticas de mídia feitas por especialistas; crítica de mídia como um gênero textual; interações sociais de crítica, nas quais receptores criticam, numa dinâmica dispersa e informal, materiais veiculados nas mídias; modos de leitura e perfis do público de crítica de mídia; formação de leitores críticos de produtos midiáticos; estudo de "teorias da crítica"; e crítica de mídia noticiosa como recurso didático-pedagógico para ensino e formação de jornalistas (SILVA; SOARES, 2013; SOARES; SILVA, 2016).

A partir dos capítulos seguintes, do II ao XII, mais do que apresentar estudos de caso sobre programas televisivos, os autores vão demonstrar a variedade de gêneros audiovisuais passíveis de crítica e diversidade de olhares teórico-metodológicos para os estudos de televisão. E fazem isso dispondo os capítulos em duas ordens de sumário. No primeiro deles, o conteúdo dos capítulos se estrutura pelos diferentes gêneros televisivos: séries; telenovela; infantil; drama; comédia; aventura; notícias; esportes; talk shows; game shows; publicidade; música. No segundo sumário, os capítulos são rearranjados pelo que os autores denominam métodos críticos: estudos de autoria; estudos culturais; estudos de gênero; estudos de recepção; dialogismo; análise do discurso; gêneros discursivos; retórica; mitologia; hermenêutica; história; sociologia; etnografia; estruturalismo; tecnologias.

Ao empreender esses dois arranjos, o livro nos propõe realizar a conexão de objetos empíricos concretos com uma escolha teórica específica, elegendo um campo no qual articular a crítica. Cada uma dessas teorias circunscreve e, concomitantemente, indica os limites e possibilidades da crítica de mídia direcionada às diferentes produções. Por esta proposta, o livro nos mostra aspectos fundamentais para a crítica de mídia hoje: (i) há diferentes jeitos de se fazer a crítica de mídia; (ii) para realizá-la é preciso levar em conta suas condições de produção e recepção; (iii) é necessário considerar objetos concretos em circulação neste ambiente midiático; (iv) pode-se demarcar a crítica pela particularidade 
dos gêneros; e (v) deve-se observar quais abordagens teórico-metodológicas orientam essas críticas.

Tais aspectos nos impõem muitos desafios, devido às tensões dos graves problemas políticos pelos quais passa a sociedade brasileira neste momento, levando-nos a algumas indagações: como politizar a crítica de mídia em sua relação com os conflitos e as desigualdades sociais, percebendo-a, também, como crítica das hegemonias? Como estudar as lutas identitárias e as disputas por reconhecimento pela via da crítica das representações midiáticas? Como examinar criticamente os discursos em circulação nas mídias e as diversas vozes neles presentes tratando-os como espaços de construção de visibilidades e invisibilidades sociais?

Nos estudos divulgados por Vande Berg e Wenner, há duas seções que nos interessam diretamente por apresentarem, justamente, aspectos da crítica sociológica e dos estudos culturais. Segundo os autores, a análise crítica implica a organização, descrição e avaliação de símbolos, articulações e padrões visando compartilhá-los com públicos variados. Tal posição atesta a importância social e cultural da televisão e, ainda, o papel da crítica na compreensão da linguagem televisiva e de suas relações com a realidade. Na análise de diferentes objetos empíricos, a crítica se vale de métodos diversos, a fim de sistematizar suas observações e interpretações e comunicá-las de maneira coerente e efetiva (VANDE BERG; WENNER, 1991, p. 9-10). Há no livro quatro artigos inseridos nas rubricas de "sociologia" e "estudos culturais". No primeiro grupo, como definido pelos autores, dois textos tratam de programas televisivos observando papeis sociais, relações e processos neles apresentados, além de usos sociais e efeitos de sentidos gerados em relação ao público (VANDE BERG; WENNER, 1991, p. 32). De acordo com os autores, alguns questionamentos são priorizados pelo método sociológico:

Em que tipo de papeis (social, ocupacional, familiar) são apresentados os personagens? Quais atributos, atitudes e comportamentos eles desempenham nesses papeis? Quais papeis são mostrados como desejáveis em termos psicológicos, emocionais, sociais ou econômicos? Quais papeis 
sociais e ensinamentos são estimulados, direta ou indiretamente, por meio desses processos?3. (VANDE BERG; WENNER, 1991, p. 32, tradução nossa)

O primeiro texto, intitulado "Listening to Dr. Ruth: the new sexual primer", ressalta o caráter social da televisão, tanto em termos ideológicos como no sentido de construir comunidades simbólicas por meio de interações culturais. Validando a compreensão de que o público não é passivo ou acrítico e ressignifica as mensagens recebidas de acordo com seus próprios contextos, Jane Banks examina um programa que tem como propósito atender tanto às expectativas por uma "comunicação massiva" como àquelas por uma "comunicação terapêutica", pressupostas na temática do programa, qual seja, sexualidade e comportamentos sexuais. As contradições derivadas desse recorte são contempladas pela autora ao enfatizar a tensão entre formas "mediadas" e formas "interpessoais" de comunicação e, também, o caráter híbrido do programa, em seu duplo propósito de entretenimento e informação (BANKS, 1991, p. 426). A transmissão de Listening to Dr. Ruth pelo rádio e em um canal de televisão por assinatura, segundo Banks, transformam a apresentadora, Ruth Westheimer, em uma figura bastante popular. Ao contrário de outras análises, a autora realiza uma crítica macroconceitual, e não uma leitura narrativa ou temática da obra, evidenciando as construções discurs7ivas do programa em termos de suas múltiplas funções para o público.

Ainda na perspectiva de uma crítica sociológica, o artigo "Sugar and spice and everything nice versus snakes and snails and puppy dogs' tails: selling social stereotypes on Saturday morning television" procura estabelecer relações entre televisão e sociedade como um processo de "compartilhamento de experiências comuns em um mundo cada vez mais fragmentado", dando às pessoas um sentido de pertencimento cultural (SCHRAG, 1991, p. 220). Escrito por Robert L. Schrag, o artigo discute comerciais de televisão exibidos aos sábados de manhã e direcionados para 
audiência infantil, examinando-os não de modo isolado, mas como um encadeamento de narrativas que constrói um conjunto coerente, coeso e com características recorrentes. Em um total de 84 propagandas exibidas nos canais NBC, $A B C$ e CBS, o texto estabelece categorias nas quais agrupar os comerciais e destaca seus principais elementos no que diz respeito às representações sociais neles presentes.

Além de perspectivas teóricas advindas da sociologia, a crítica empreendida pelos estudos culturais representa um campo profícuo para análises da crítica midiática. Desde as décadas de 1970 e 1980, com os estudos culturais ingleses trabalhados, primeiramente, por Raymond Williams e Stuart Hall, e desenvolvidos posteriormente por John Fiske e John Hartley, entre outros, temos uma combinação de análises críticas de diversos programas e gêneros televisivos. Esses conceitos expandem-se para outros territórios, tendo nos estudos norte-americanos e latino-americanos alguns seguidores que, juntos, consolidam um campo de estudos de televisão visando alargar a ação da crítica. A contribuição trazida pelos estudos culturais

pressupõe que ideologia, estruturas econômicas, estrutura social, e cultura são inseparáveis. Essa perspectiva crítica está fundada em uma combinação de teorias político-econômicas neomarxistas, estruturalismo e semiótica, além da teoria psicanalítica freudiana. ${ }^{4}$ (VANDE BERG; WENNER, 1991, p. 27, tradução nossa)

Ao examinar, sobretudo, as variáveis de classe, gênero e etnia, os estudos culturais analisam os programas televisivos tomando como centrais, segundo os autores, os conceitos de ideologia, hegemonia e discurso. Algumas perguntas são aqui priorizadas:

A quem o programa se dirige? Que tipos de relações sociais são construídas ou reproduzidos na obra e no público que assiste a esse programa? Quais discursos definíveis (tais como masculinidade, individualismo, economia capitalista, educação etc.) são colocados na narrativa como naturais, ou como pontos de vista preferenciais para enxergar o mundo e 
os diversos papeis sociais? Quais são os interesses mais bem atendidos por essa visão? A obra permite ao receptor construir leituras significativamente alternativas ou mesmo opostas em relação às ideologias dominantes ${ }^{5}$ (VANDE BERG; WENNER, 1991, p. 28, tradução nossa)

Nessa visada culturalista, o livro traz dois textos: "The late-night talk show: humor in fringe television", de Rodney A. Buxton, e "The discourses of TV quiz shows, or school + luck = success + sex", de John Fiske. O primeiro deles parte da premissa de que a televisão representa um importante meio tanto na difusão de informação, como de entretenimento, refletindo e influenciando correntes ideológicas na arena cultural da sociedade. Ainda que os valores dominantes prevaleçam na maior parte da programação televisiva, Buxton destaca que isso não implica a exclusão de valores alternativos, o que foi se tornando ainda mais presente nas últimas décadas por meio da ênfase, seguidamente maior, em debates sobre questões identitárias e sociais. Segundo o autor, a própria sobrevivência da televisão enquanto meio dependeria desses espaços contraditórios e, muitas vezes, a incorporação de novos valores é determinante para sua continuidade, ampliando as fronteiras das representações propostas ao público.

A televisão seria um sistema discursivo entre outros, participando das disputas ideológicas presentes na sociedade: "Entretanto, a televisão, devido a sua centralidade social e cultural, não pode ser subestimada em sua força discursiva de ou corroborar, ou romper a matriz ideológica dominante"6 (BUXTON, 1991, p. 412, tradução nossa). Para demonstrar suas hipóteses, Buxton analisa programas em formato de talk show exibidos em horário noturno que, segundo o autor, são organizados de modo menos linear e mais fluido, sem seguir uma forma narrativa pré-determinada e, portanto, abertos a momentos de imprevisibilidade e surpresa. Questões ligadas às celebridades

No original: "To whom is the program addressed? What kinds of social relationships are constructed or reproduced in the text and in audiences viewing the program? What definable discourses (such as masculinity, individualism, capitalist economics, education, etc.) does the narrative affirm as natural, preferred ways of viewing the world and various social roles? Whose interests are best served by this view? Does the text allow the viewer to construct meaningful alternative or even opposing readings that question the dominant ideologies?". 
midiáticas e às estratégias humorísticas são discutidas no artigo, comparando os programas de três apresentadores norte-americanos (Johnny Carson, Joan Rivers e David Letterman) e apontando seus efeitos de sentido sobre o público.

Por fim, o outro artigo selecionado parte de uma questão bastante presente nas pesquisas sobre televisão: "De que modo um programa pode servir aos interesses econômicos e ideológicos da classe dominante por um lado e, ainda assim, tornar-se popular entre grupos sociais a ela subordinados?"7 (FISKE, 1991, p. 445, tradução nossa). Observando o fato de alguns programas televisivos se tornarem extremamente populares, enquanto muitos outros não atingem esse destaque entre o público, John Fiske, importante teórico dos estudos de televisão, ressalta que essa mídia é uma das principais propagadoras de múltiplos significados em nossas sociedades. Tal processo possui sempre uma dimensão ideológica e, consequentemente, não é jamais neutro, defendendo os interesses de determinados grupos sociais - ainda que nem sempre esses sejam os significados percebidos pelo público (FISKE, 1991, p. 445). Logo, o papel da crítica seria explicitar esses significados prevalentes nos programas televisivos e interpretá-los de acordo com a ideologia dominante, mas não sem problematizar - o que é um dos objetivos do artigo - o papel ativo do público na apropriação e interpretação desses programas.

Para Fiske, a articulação entre os sistemas de produção, recepção e as obras se faz em um delicado equilíbrio, no qual "é necessário, então, um grau de abertura na obra para dar conta da variedade de experiências sociais dos leitores, mas esta abertura deve estar ancorada em um núcleo bem definido de interpretações preferenciais ou produzirá uma anarquia textual, social e ideológica"8 (FISKE, 1991, p. 461, tradução nossa). As "interpretações preferenciais" demarcam os limites ideológicos nos quais outros sentidos podem ser negociados pelo público, validando as ideologias dominantes, mas,

$7 \quad$ No original: "So how can a program serve the economic and ideological interest of the dominant on the one hand and yet be made popular by subordinate social groups on the other?". 
simultaneamente, possibilitando espaços de interação entre os receptores e os discursos presentes nas obras.

\section{Crítica de mídia, justiça social e sujeitos políticos}

Os aportes advindos das pesquisas relatadas por Vande Berg e Wenner no campo da crítica televisiva nos anos 1990 nos trazem balizas nas quais assentamos questionamentos mais gerais sobre a crítica de mídia na atualidade. $\mathrm{Na}$ intenção de estabelecer relações entre cultura e sociedade (ou entre estética e política) que extrapolem a oposição simplista entre forma e conteúdo, a crítica nos apresenta desafios visando equilibrar análises imanentistas (sejam elas formalistas, fenomenológicas ou estilísticas) e análises transcendentes (sejam elas históricas, sociológicas, psicológicas ou filosóficas).

Trata-se de um debate de extensa tradição no campo da arte, quando a crítica evoca sua maior ou menor autonomia em relação a seus contextos de produção. A tensão entre valores internos e aspectos externos retorna com grande potência nos cenários contemporâneos, em que lutas identitárias e disputas por reconhecimento se tornam, cada vez mais, parâmetros para o exercício da crítica cultural, especialmente aquela dedicada a produções em circulação nas mídias digitais e redes sociais online.

Por estas bases, o desenho de como uma determinada obra é organizada (a enunciação), e não apenas os temas dos quais trata (os enunciados), deve ser avaliada ao se empreender a crítica de obras artísticas ou midiáticas, visando alcançar equilíbrio entre seus elementos constituintes e aqueles que aciona externamente. Esta discussão diz respeito, ainda, à questão sobre os alcances e os limites da representação da realidade por meio de distintas mediações de ordem narrativa e discursiva que estão presentes nas práticas culturais. Ou seja, ao crítico cultural não caberia explorar, na obra analisada, apenas os traços de acontecimentos do mundo concreto, mas nela perceber marcas singulares e instauradoras de novas realidades, em que a criação não é apenas um exercício de interpretação dos fatos, mas também um gesto estético de inovação na linguagem. 
Não pretendemos acompanhar essa disputa em seu caráter excludente ou dicotômico. É um caminho do meio que visamos percorrer, considerando as condições específicas de elaboração e sustentação de uma obra enquanto manifestação estética e, ao mesmo tempo, empreendendo uma análise crítica que possa articular seus aspectos históricos, sociais e políticos. No campo da crítica literária, assim como na crítica cinematográfica, há diferentes contribuições a este debate. Nicole Brenez, em seu artigo "A crítica como conceito, exigência e práxis", nos lembra que

Antes de ser uma atividade remunerada, a crítica consiste em uma noção rica em ideais e possuidora de uma história complexa. O fato de que hoje, no campo do cinema, não existam mais relações entre estas duas acepções (a crítica profissional por um lado, a crítica como conceito estruturador do pensamento da época das Luzes por outro) não apenas não os autoriza a dissociar-se, mas obriga mesmo a pensar as relações efetivas e as articulações dissociadas entre ambas as concepções. [...] A conceitualização da atividade crítica das Luzes coube, no entanto, à filosofia alemã. (BRENEZ, 2014a)

Ao investigar a crítica como conceito, Brenez parte das origens teóricas idealistas da significação transcendental de análise dos meios e dos limites do conhecimento, de teorias das condições a priori de toda experiência. Ao observar a crítica como exigência, a autora olha para as exigências materialistas e para a própria história da crítica em seus componentes políticos. E ao tomar a crítica como práxis, está dizendo do trabalho crítico - e no seu caso, trabalhos com artes fílmicas em geral (cinema, vídeo, digital). Nas palavras da autora, uma análise crítica deve voltar-se não apenas para a decifração do filme ou para as evidências no filme, mas, sobretudo, àquilo que ele postula. Em outras palavras, deve perguntar-se, afinal, o que ele está levando em conta antes de existir enquanto filme ou de produzir algum efeito: "Como um filme postula o que é uma coisa? Não só a forma como trata, por exemplo, um animal, ou uma mulher, ou um jardim, ou qualquer motivo, mas o que postula? Não é o que está no filme, mas o que um filme tem que pensar para existir" (BRENEZ, 2014b).

Essa inquietação está relacionada ao lugar da ideologia e, em vista disso, a aspectos discursivos presentes na tessitura das obras, para além de seu caráter 
narrativo, indicando que se trata, sempre, de uma construção na linguagem, e não algo observável no plano das imagens:

Tudo o que não se está dizendo explicitamente, mas o que se pensa, o que se acredita, antes de considerar um fenômeno. Cada filme, seja radical ou, é claro, ideológico, tem seus pressupostos: as coisas que ele não diz, mas que estão trabalhadas no filme. Por exemplo: o que um filme pressupõe para representar uma mulher? Mas também uma guerra. O que você pressupõe sobre o que é uma guerra para representar uma guerra? Esse é um enorme campo de pensamento. (BRENEZ, 2014b)

Na combinatória desses três pilares da crítica - conceito, exigência, práxis -, devemos indagar como estabelecer parâmetros pelos quais realizar a crítica de mídia, movimento que indicamos a seguir. É importante lembrar que, no caso de produções midiáticas, os campos da produção (autoria) e da recepção (leitura) são indissociáveis e, muitas vezes, intercambiáveis, o que nos obriga a olhar as obras (verbais, visuais, sonoras ou audiovisuais) sempre em um circuito crítico, do qual participam tanto os criadores como seu público, incluindo a crítica profissional e aquela mais dispersa, seja ela especializada ou informal.

Ao assumirmos que a crítica contemporânea é um processo de interpretação e de produção de sentidos sobre os textos, a dimensão social se expressa desde sua criação e engloba, de forma mais evidente, sua circulação. Ainda que o mundo histórico não possa ser imposto à análise das obras, não podemos observálas como fechadas em si mesmas. Devemos levar também em consideração como os acontecimentos do mundo estão nelas construídos, indo do texto para o contexto e, inversamente, retornando deste para a materialidade das obras. Neste empreendimento, os aportes teóricos e metodológicos da teoria crítica e dos estudos culturais surgem como possibilidades para a crítica de mídia.

Em texto no qual trata da retomada da teoria crítica nos estudos comunicacionais, Vera França parte, justamente, da amplitude desta matriz teórica que teria como parâmetro a relação e o comprometimento da mídia com o interesse coletivo e com a justiça social. Ao falar do "terceiro momento" da teoria crítica (em sequência ao percurso de "duas matrizes" e "segundas escolas"), 
França discute uma "nova orientação". Em diálogo com Boltanski, que também identifica essa reversão, a autora problematiza a crítica no cenário contemporâneo:

Nos primeiros anos do século XXI, movimentos críticos acontecem em vários âmbitos da sociedade - nas relações de trabalho, no seio das empresas, na reação aos cortes das políticas públicas. A mesma tendência se verifica no campo acadêmico, e vários autores - nos campos da filosofia e da sociologia - retomam a tradição da perspectiva crítica e promovem debates propondo seu resgate e atualização. (FRANÇA, 2018, p. 24)

Esta "nova orientação" no "terceiro momento" da teoria crítica, como ressalta França, surge no âmbito acadêmico como um "questionamento crescente" de vários autores ao enfatizarem a "questão do reconhecimento" e a "questão identitária", tendência por ela problematizada:

As limitações e riscos apontados dizem respeito ao encobrimento das relações de classe e às dinâmicas estruturais, ao fomento dos fundamentalismos, ao abandono dos projetos globais em nome de particularismos e, em última instância, ao que seria uma concessão ao individualismo liberal - privilegiando as satisfações individuais. (FRANÇA, 2018, p. 23)

Examinando este deslocamento, França nos alerta quanto aos perigos de se sobrepor "lutas e defesas de interesses específicos" em detrimento de "projetos coletivos": "o que essa crítica aponta é a tendência ou o risco de que o aprofundamento das críticas em eixos verticais (particularidades) estaria se fazendo em detrimento da compreensão dos eixos horizontais que unem/dividem a sociedade de classes (a dinâmica estrutural)" (FRANÇA, 2018, p. 24).

No terreno das lutas e movimentos sociais, portanto, estariam mais visíveis, no cenário contemporâneo, os recuos da crítica. Ainda em diálogo com Boltanski, França informa que o sociólogo sinaliza forte distinção entre dois momentos (os anos 1965-1975 e a atualidade), que diz respeito ao efeito da crítica, ao seu poder e à sua capacidade de atuar na realidade - para o sociólogo parece que "o aumento da presença da crítica não se faz acompanhar de um crescimento no 
mesmo grau de um poder da crítica, como se esta não tivesse mais pegada sobre a realidade" (BOLTANSKI, 2015 apud FRANÇA, 2018, p. 24, grifo da autora). Resulta, então, segundo a autora, que as formas de resistência crítica e reflexiva encontram grande dificuldade para ultrapassar as representações da realidade econômica, social ou política que as instituições infundem e para enfrentar o poder destas instituições de impor quadros e referências de leitura das coisas do mundo (FRANÇA, 2018).

Para a autora, uma boa teoria crítica seria aquela que resgata os elementos estruturais sem menosprezar a agência humana e a força da experiência:

\footnotetext{
É essa a contribuição que a teoria crítica deve trazer para os estudos comunicacionais: a leitura e compreensão da inserção social dos sujeitos, do alcance de sua experiência, dos elementos e representações que essa inserção Ihes torna disponíveis, das forças sociais que agem sobre ele e do seu maior ou menor poder de resistência e reação nesse jogo de forças. (FRANÇA, 2018, p. 24)
}

Ao levarmos em conta as produções midiáticas (verbais, visuais, sonoras, audiovisuais) e a grande variedade de modos de se fazer a crítica de mídia, assumimos como premissa a centralidade do papel político da crítica. Em relação à diversidade das práticas culturais, essas duas perspectivas teóricas teoria crítica e estudos culturais -levam a crítica a responder às recomposições do social por meio de lutas identitárias, equilibrando a equação salientada anteriormente por França.

Pela perspectiva dos estudos culturais, a contribuição sugerida para se trabalhar a crítica de mídia está voltada ao estabelecimento das interfaces entre cultura, representação e crítica social. Em seus estudos, Hall elabora uma possibilidade para se fazer a crítica das representações por meio da noção de "articulação", que contribui para a reflexão sobre como surgem os elementos ideológicos, formando discursos (a exemplo do que foi destacado por Brenez), e como esses discursos organizam sentidos para certos sujeitos políticos em conjunturas específicas. Com isso, os estudos culturais contribuem para a apreensão dos modos pelos quais práticas simbólicas operam em situações históricas concretas, definindo as representações como construtos históricos e ideológicos: 
A ênfase da abordagem discursiva recai invariavelmente sobre a especificidade histórica de uma forma particular ou de um "regime" de representação, e não sobre a "linguagem" enquanto tema mais geral. Isto é, seu foco incide sobre linguagens ou significados e de que maneira eles são utilizados em um dado período ou local. (HALL, 2016, p. 27)

Nessa perspectiva, a articulação entre discurso e hegemonia configurase como estruturante das relações sociais, rompendo as dicotomias simplistas que insistem em cristalizar os processos de construção da representação em essencialismos. Mais do que se perguntar sobre como os sentidos estão articulados nos discursos, privilegiando seu aspecto formal, os estudos culturais indagam sobre os processos que permitem que certos sentidos sejam produzidos e produzam significados sociais, pois examinam

não apenas como a linguagem e a representação produzem sentido, mas como o conhecimento elaborado por determinado discurso se relaciona com o poder, regula condutas, inventa ou constrói identidades e subjetividades e define o modo pelo qual certos objetos são representados, concebidos, experimentados e analisados. (HALL, 2016, p. 27)

Enfatizando o papel ativo e concreto das representações - seu caráter político em relação às práticas sociais e aos espaços de poder -, Hall define os discursos como "maneiras de se referir a um determinado tópico da prática ou sobre ele construir conhecimento: um conjunto (ou constituição) de ideias, imagens e práticas que suscitam variedades no falar, formas de conhecimento e condutas relacionadas a um tema particular, atividade social ou lugar institucional na sociedade" (HALL, 2016, p. 26). Assim, o discurso é o lócus onde tais embates se manifestam e, ao mesmo tempo, aquilo pelo que se luta, atribuindo à cultura uma dimensão simbólica não representacional e definindo-a como um sistema de partilha e de estabelecimento do que é comum a determinada sociedade. Isto posto, a representação, 
prioridades, com seus membros (e não membros), suas regras e instituições. Nesse contexto, da "representação como política", não ter voz ou não se ver representado pode significar nada menos que opressão existencial. (HALL, 2016, p. 13)

Desenvolvida por Hall em diversos estudos para se contrapor a concepções deterministas ou idealistas, a noção de "articulação" pressupõe o estabelecimento de conexões entre práticas sociais e práticas discursivas, trazendo para primeiro plano a integração entre os contextos de produção e recepção implicados na criação e circulação de objetos culturais variados, inclusive aqueles propostos pelas mídias. Neste cenário, afirmamos que novos contextos políticos, culturais e sociais exigem reposicionamentos da crítica - especialmente a crítica midiática -, sendo necessário encontrar políticas da crítica que possam responder a esses contextos em seus aspectos históricos e ideológicos. Ao definir os conceitos de "codificação" e "decodificação" como processos por meio dos quais produtores e receptores estabelecem contratos comunicacionais para circulação e apropriação de produções culturais, especialmente audiovisuais, Hall nos oferece caminhos para tal empreendimento.

A posição defendida por ele contrapõe-se às tradicionais análises funcionalistas ou positivistas da comunicação, que estabelecem relações lineares e causais entre os conteúdos das mensagens televisivas e sua interpretação pelos espectadores, vistos como passivos e, por isso, passíveis de serem manipulados por esses blocos uniformes de mensagens. Em linhas gerais, Hall propõe ao menos três vias de concebermos os processos de codificação e decodificação das imagens televisivas apresentadas: a posição hegemônica dominante, a posição negociada e a que se faz por oposição à dominante (HALL, 2003). Ao atribuir ao receptor a possibilidade de se apropriar de sentidos para além daqueles previstos pelo emissor, Hall problematiza a visão corrente de que os significados são homogêneos ou unívocos, posicionandose contra "uma noção particular de conteúdo entendido como um sentido ou uma mensagem pré-formada e fixa, que pode ser analisada em termos de transmissão do emissor para o receptor" (HALL, 2003, p. 354). 
Tais definições antecipam os elementos apresentados sobre as relações entre discurso, representação e ideologia, já que aquilo que denominamos mensagem seria uma "estrutura complexa de significados que não é tão simples como se pensa. A recepção não é algo aberto e perfeitamente transparente, que acontece na outra ponta da cadeia de comunicação. E a cadeia comunicativa não opera de forma unilinear" (HALL, 2003, p. 354). Essa concepção possibilita respondermos a debates contemporâneos no que diz respeito às articulações entre textos e contextos, obras e públicos, hegemonias e resistências, em processos históricos cada vez mais marcados por embates discursivos e narrativos entre os diferentes atores sociais.

\section{Apontamentos finais}

Ao privilegiarmos as contribuições da teoria crítica e dos estudos culturais para o estabelecimento de parâmetros nos quais exercitar a crítica de mídia, algumas tarefas nos são postas. A primeira delas diz respeito à necessidade de se produzir mais textos críticos em contato direto com as obras analisadas, não tanto como a aplicação de um método ou uma fórmula, mas como um meio caminho entre a crítica textual e a crítica social, principalmente para compreensão das variadas produções multimidiáticas disponibilizadas em plataformas digitais e redes sociais. A segunda diz respeito à urgência em tratarmos a crítica em geral, e a crítica midiática em particular, como um fazer histórico e em estrita conexão com seu tempo, o que significa atestar seu caráter eminentemente político e seu compromisso ético no que diz respeito aos sujeitos nas e das representações figuradas nas mídias.

Finalmente, um terceiro aspecto se destaca, impulsionado pelas crescentes lutas identitárias e disputas por reconhecimento social, pautadas pelas mídias e delas demandando posturas mais firmes. A exigência de posicionamentos a respeito de obras culturais polêmicas envolvendo representações de minorias, reforço ou desconstrução de estigmas e questionamento de preconceitos e estereótipos naturalizados no tecido social obriga a um constante reposicionamento da crítica midiática e ao estabelecimento de diálogos entre a crítica e as demandas por reconhecimento. É nesse sentido que, inspiradas pelas correntes teóricas privilegiadas 
neste artigo, vislumbramos um trajeto no qual a crítica de mídia possa ser pensada como crítica das representações e das hegemonias, elegendo os conceitos de identidade, visibilidade e reconhecimento como operadores conceituais.

Entre a autonomia da crítica (os elementos internos à obra) e a crítica social (os elementos a ela externos), vemos possibilidades para o exercício da crítica de mídia em seus compromissos políticos e comprometimentos éticos com os sujeitos do tempo presente. Tal equilíbrio pressupõe assumirmos que a crítica não se encontra separada da sociedade da qual faz parte e tampouco atua apenas a partir de um engajamento ativista e posicionado exterior às produções culturais por ela analisadas. É no caminho do meio que situamos seu percurso, interpelando os discursos circulantes nas e pelas mídias e sendo por eles desafiados a politizar um tanto mais as análises críticas e suas perspectivas filosóficas.

\section{Referências}

BANKS, J. Listening to Dr. Ruth: the new sexual primer. In: VANDE BERG, L. R.; WENNER, L. A. (org.). Television criticism: approaches and applications. Nova York: Longman, 1991. p. 425-441.

BRENEZ, N. A crítica como conceito, exigência e práxis. Tradução de: Luiz Soares Junior. Revista Cinética: Cinema e Crítica, [s. I.], 10 fev. 2014a. Em campo. Disponível em: http://bit.ly/2PIv3HQ. Acesso em: 29 set. 2019.

BRENEZ, N. Cada filme é um laboratório. [Entrevista cedida a] Raul Arthuso e Victor Guimarães. Revista Cinética: Cinema e Crítica, [s. I.], 10 fev. 2014b. Em campo. Disponível em: http://bit.ly/2ogZQug. Acesso em: 29 set. 2019.

BUXTON, R. A. The late-night talk show: humor in fringe television. In: VANDE BERG, L. R.; WENNER, L. A. (org.). Television criticism: approaches and applications. Nova York: Longman, 1991. p. 411-424. 
FISKE, J. The discourses of TV quiz shows, or school + luck = success + sex. In: VANDE BERG, L. R.; WENNER, L. A. (org.). Television criticism: approaches and applications. Nova York: Longman, 1991. p. 445-462.

FRANÇA, V. V. Transformações e atualidade da teoria crítica. Rumores, São Paulo, v. 12, n. 23, p. 13-31, 2018. Disponível em: http://bit.ly/343EIMW. Acesso em: 25 out. 2019.

HALL, S. Da diáspora: identidades e mediações culturais. Belo Horizonte: Editora da UFMG, 2003.

HALL, S. Cultura e representação. Rio de Janeiro: Apicuri: Editora PUC-Rio, 2016.

SCHRAG, R. L. Sugar and spice and everything nice versus snakes and snails and puppy dogs' tails: selling social stereotypes on Saturday morning television. In: VANDE BERG, L. R.; WENNER, L. A. (org.). Television criticism: approaches and applications. Nova York: Longman, 1991. p. 220-232.

SILVA, G.; SOARES, R. L. Para pensar a crítica de mídias. Revista Famecos, Porto Alegre, v. 20, n. 3, p. 820-839, 2013. Disponível em: http://bit.ly/2WfKpyU. Acesso em: 25 out. 2019.

SOARES, R. L.; SILVA, G. Lugares da crítica na cultura midiática. Comunicação, mídia e consumo, São Paulo, v. 13, n. 37, p. 9-28, 2016. Disponível em: http://bit.ly/346j1qa. Acesso em: 25 out. 2019.

VANDE BERG, L. R.; WENNER, L. A. (org.). Television criticism: approaches and applications. Nova York: Longman, 1991. 